\title{
The Evolutionary Chromosome Translocation 4;19 in Gorilla gorilla is Associated with Microduplication of the Chromosome Fragment Syntenic to Sequences Surrounding the Human Proximal CMT1A-REP
}

\author{
Pawel Stankiewicz, ${ }^{1}$ Sung-Sup Park, ${ }^{1}$ Ken Inoue, ${ }^{1}$ and James R. Lupski ${ }^{1,2,3}$ \\ ${ }^{1}$ Department of Molecular and Human Genetics, Baylor College of Medicine, Houston, Texas 77030, USA; ${ }^{2}$ Department of \\ Pediatrics, Baylor College of Medicine, Houston, Texas 77030, USA
}

\begin{abstract}
Many genomic disorders occur as a result of chromosome rearrangements involving low-copy repeats (LCRs). To better understand the molecular basis of chromosome rearrangements, including translocations, we have investigated the mechanism of evolutionary rearrangements. In contrast to several intrachromosomal rearrangements, only two evolutionary translocations have been identified by cytogenetic analyses of humans and greater apes. Human chromosome 2 arose as a result of a telomeric fusion between acrocentric chromosomes, whereas chromosomes 4 and 19 in Gorilla gorilla are the products of a reciprocal translocation between ancestral chromosomes, syntenic to human chromosomes 5 and 17, respectively. Fluorescence in situ hybridization (FISH) was used to characterize the breakpoints of the latter translocation at the molecular level. We identified three BAC clones that span translocation breakpoints. One breakpoint occurred in the region syntenic to human chromosome 5q13.3, between the HMG-CoA reductase gene (HMGCR) and RAS p21 protein activator 1 gene (RASAI). The second breakpoint was in a region syntenic to human chromosome $17 \mathrm{pl} 2$ containing the $24 \mathrm{~kb}$ region-specific low-copy repeat-proximal CMT1A-REP. Moreover, we found that the $t(4 ; 19)$ is associated with a submicroscopic chromosome duplication involving a 19p chromosome fragment homologous to the human chromosome region surrounding the proximal CMTIA-REP. These observations further indicate that higher order genomic architecture involving low-copy repeats resulting from genomic duplication plays a significant role in karyotypic evolution.
\end{abstract}

Several genomic disorders result from homologous recombination events between region specific low-copy repeats (LCRs). To understand mechanisms leading to chromosome rearrangements, we have investigated the basis of evolutionary breakpoints using cytogenetic approaches. The high resolution G-banding and molecular-cytogenetic comparisons of karyotypes of human (Homo sapiens, HSA), chimpanzee (Pan troglodytes, PTR and Pan paniscus, PPA), gorilla (Gorilla gorilla, GGO), and orangutan (Pongo pygmaeus, PPY) showed that they differ mostly by intrachromosomal rearrangements: peri- and paracentric inversions as well as heterochromatic variations (Yunis and Prakash 1982; Jauch et al. 1992). Twelve inversions and two chromosome translocations have been identified cytogenetically, enabling distinction between human and gorilla karyotypes. After human/chimpanzee divergence, <5.5 million years ago (Mya), (Kumar and Hedges 1998), telomeric fusion of two ancestral acrocentric chromosomes resulted in the generation of human chromosome 2 (Turleau et al. 1972; Dutrilaux 1979; Yunis and Prakash 1982; Wienberg et al. 1994). The gorilla unique reciprocal translocation $\mathrm{t}(4 ; 19)$ arose between ancestral chromosomes homolo-

${ }^{3}$ Corresponding author.

E-MAIL jlupski@bcm.tmc.edu; FAX (713) 798-5073.

Article and publication are at http://www.genome.org/cgi/doi/10.1101/ gr.181101. gous to human chromosomes 5 and $17 \sim 6.7$ Mya (Dutrillaux et al. 1973; Yunis and Prakash 1982; Stanyon et al. 1992; Kumar and Hedges 1998). In contrast to these few rearrangements, during speciation of gibbon (Hylobatidae, HLA) at least 31, 33, and 39 chromosome translocations occurred in Hylobates concolor, Hylobates syndactylus, and Hylobates hoolock, respectively (Koehler et al. 1995a,b; Yu et al. 1997). In Hylobates lar, human autosomes are divided into 51 separate HLA segments (Jauch et al. 1992).

In the majority of fluorescence in situ hybridization investigations of primate chromosomes, human chromosome painting probes have been applied (Jauch et al. 1992; Ried et al. 1993; Wienberg et al. 1997; Müller et al. 1997; Toder et al. 1998). To our knowledge, very few rearrangements in greater and lesser apes (superfamily Hominoides) have been characterized using FISH with unique sequence probes or other molecular techniques (Arnold et al. 1996; Haaf and Bray-Ward 1996; McConkey 1997; Müller et al. 2000). Recently, Nickerson and Nelson (1998) molecularly defined five evolutionary breakpoints of pericentric inversions on chimpanzee chromosomes, equivalent to human chromosomes 4,9 , and 12 . Interestingly, the breakpoint on chimpanzee chromosome homologous to HSA 12q15 has been found to be associated with a submicroscopic duplication (Nickerson 2000).

The chromosome 19 breakpoint of the evolutionary gorilla $\mathrm{t}(4 ; 19)$ maps to the human chromosome 17p11.2-p12 
syntenic region. This human genomic region encompasses several low-copy repeat sequences and is involved in relatively frequent constitutional genomic rearrangements resulting in genomic disorders (Lupski 1998). Charcot-Marie-Tooth disease type $1 \mathrm{~A}$ and hereditary neuropathy with liability to pressure palsy (HNPP) are caused by reciprocal duplication or deletion of a $1.4 \mathrm{Mb}$ genomic fragment within $17 \mathrm{p} 12$, respectively, which is mediated by flanking low-copy repeats CMT1A-REPs (Reiter et al. 1996). In $>90 \%$ of cases, SmithMagenis syndrome (SMS) and dup(17)(p11.2p11.2) syndrome are caused, respectively, by reciprocal deletion and duplication of an $\sim 4 \mathrm{Mb}$ chromosome segment in $17 \mathrm{p} 11.2$, also flanked by LCRs termed SMS-REPs (Chen et al. 1997; Potocki et al. 2000).

Here, we present the results of detailed molecular cytogenetic studies of the evolutionary translocation $4 ; 19$ in gorilla using FISH with human BAC, PAC, and cosmid clones. Our findings indicate that genome evolutionary breakpoints may overlap with human genomic regions susceptible to constitutional rearrangements.

\section{RESULTS}

Our molecular approach to investigate the breakpoints associated with the evolutionary reciprocal translocation yielding Gorilla gorilla chromosomes 4 and 19 was to determine which human genomic clones correspond to the syntenic chromosome regions between human and gorilla. On the basis of the comparative G-banding ideograms of human and gorilla chromosomes (Yunis and Prakash 1982), we assigned the gorilla translocation breakpoints to the human chromosome bands 5q13.3 and 17p11.2-p12. Since the 17p11.2-p12 interval contains both the 17p12 (CMT1A) and 17p11.2 (SMS) chromosomal regions, we investigated whether the evolutionary breakpoint occurred in either interval. Human genomic clones identified within these regions were then used as probes in FISH mapping studies of gorilla chromosomes (Table 1). Two human clones, PAC RP1-39O20 and BAC RP11209J20, mapping to the 17p12 (CMT1A) and 17p11.2 (SMS) regions, respectively, were co-hybridized onto gorilla chromosomes. We found that they are localized on gorilla chromosomes 4 and 19, respectively, indicating that the evolutionary breakpoint occurred between the CMT1A and SMS regions.

To refine the location of this important translocation breakpoint, we applied several clones mapping between these two human genomic clones as probes to gorilla chromosomes. These probes represent an ordered array of human genomic clones (arranged from the telomere to centromere direction) in proximal 17p (Table 1). Four human chromosome 17 probes (PACs RP1-140M10 and RP1-39O20, BAC RP11-726O12, and cosmid 96G3) produced one hybridization signal on gorilla chromosome 4 , while four BACs (CTD3157E16, RP11-692E18, RP11-651L9, and RP11-209J20) produced one hybridization signal on the gorilla chromosome 19 (Fig. 1a,b). Two HSA 17 BACs (RP11-385D13 and RP11640I15) showed signals on both gorilla chromosomes 4 and 19 (Fig. 1c), demonstrating that they span the gorilla $t(4 ; 19)$ evolutionary translocation breakpoint.

Table 1. The Telomere-Centromere Ordered List of Human Clones Used in FISH Studies

\begin{tabular}{|c|c|c|c|c|c|c|}
\hline \multirow[b]{2}{*}{ Probe } & \multirow[b]{2}{*}{ Vector } & \multirow[b]{2}{*}{ Source } & \multirow{2}{*}{\multicolumn{2}{|c|}{ Location in human }} & \multicolumn{2}{|c|}{ Signal on gorilla chromosome } \\
\hline & & & & & 4 & 19 \\
\hline \multirow{9}{*}{$\begin{array}{l}\text { RP1-39O20 } \\
\text { RP1-140M10 } \\
\text { RP11-726O12 } \\
96 G 3 \\
\text { RP11-385D13 } \\
4 A 10 \\
59 E 9 \\
4 G 3 \\
123 F 7 \\
\text { RP11-640115 }\end{array}$} & PAC & \multirow{2}{*}{ RPCI-1 library } & \multirow{2}{*}{\multicolumn{2}{|c|}{$\begin{array}{l}\text { PMP22 } \\
\text { prox. CMT1A-REP-PMP22 }\end{array}$}} & + & - \\
\hline & $\overline{B A C}$ & & & & + & - \\
\hline & \multirow{3}{*}{$\begin{array}{l}\text { cosmid } \\
\text { BAC }\end{array}$} & 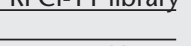 & & & + & - \\
\hline & & RPCI-11 library & \multirow{10}{*}{ 17p11.2-p12 } & \multirow{7}{*}{ around prox. CMT1A-REP } & + & + \\
\hline & & \multirow{4}{*}{$\begin{array}{l}\text { Murakami and } \\
\text { Lupski } 1996\end{array}$} & & & + & + \\
\hline & \multirow{3}{*}{ cosmid } & & & & + & + \\
\hline & & & & & + & + \\
\hline & & & & & + & + \\
\hline & \multirow{16}{*}{ BAC } & \multirow{16}{*}{$\begin{array}{l}\text { RPCI-11 } \\
\text { and } \\
\text { CITB libraries }\end{array}$} & & & + & + \\
\hline $\begin{array}{l}\text { CTD-3157E16 } \\
\text { RP11-692E18 }\end{array}$ & & & & & - & + \\
\hline RP11-692E18 & & & & \multirow{3}{*}{ SMS-CMT1A } & - & + \\
\hline RP11-651L9 & & & & & - & + \\
\hline RP11-209|20 & & & & & - & + \\
\hline RP11-639J10 & & & \multirow{11}{*}{$5 q 13.3$} & $N R 2 F 1$ & - & + \\
\hline RP11-393G17 & & & & MEF2C & - & + \\
\hline RP11-207B2 & & & & & - & + \\
\hline CTC-2248H3 & & & & СКMT2 & - & + \\
\hline RP11-580L9 & & & & & - & + \\
\hline CTD-2064K14 & & & & RASA1 & - & + \\
\hline СТC-428H11 & & & & $\begin{array}{l}\text { RASA1, HRH2, COL4A3BP, } \\
\text { CCNH, HMGCR }\end{array}$ & $+(2 x)$ & + \\
\hline CTD-2154016 & & & & $H M G C R$ & + & - \\
\hline RP11-414A11 & & & & $H M G C R$ & + & - \\
\hline CTC-431G16 & & & & & + & - \\
\hline CTD-2156N14 & & & & & + & - \\
\hline
\end{tabular}

Clones are ordered from telomere (top) to centromere (bottom). The probes associated with the described duplication are shaded. Chromosome 5 q13.3 overlapping BAC clones are in bold.

+ , Signal present; -, signal absent; $2 x$, signal duplicated on the same chromosome arm. 

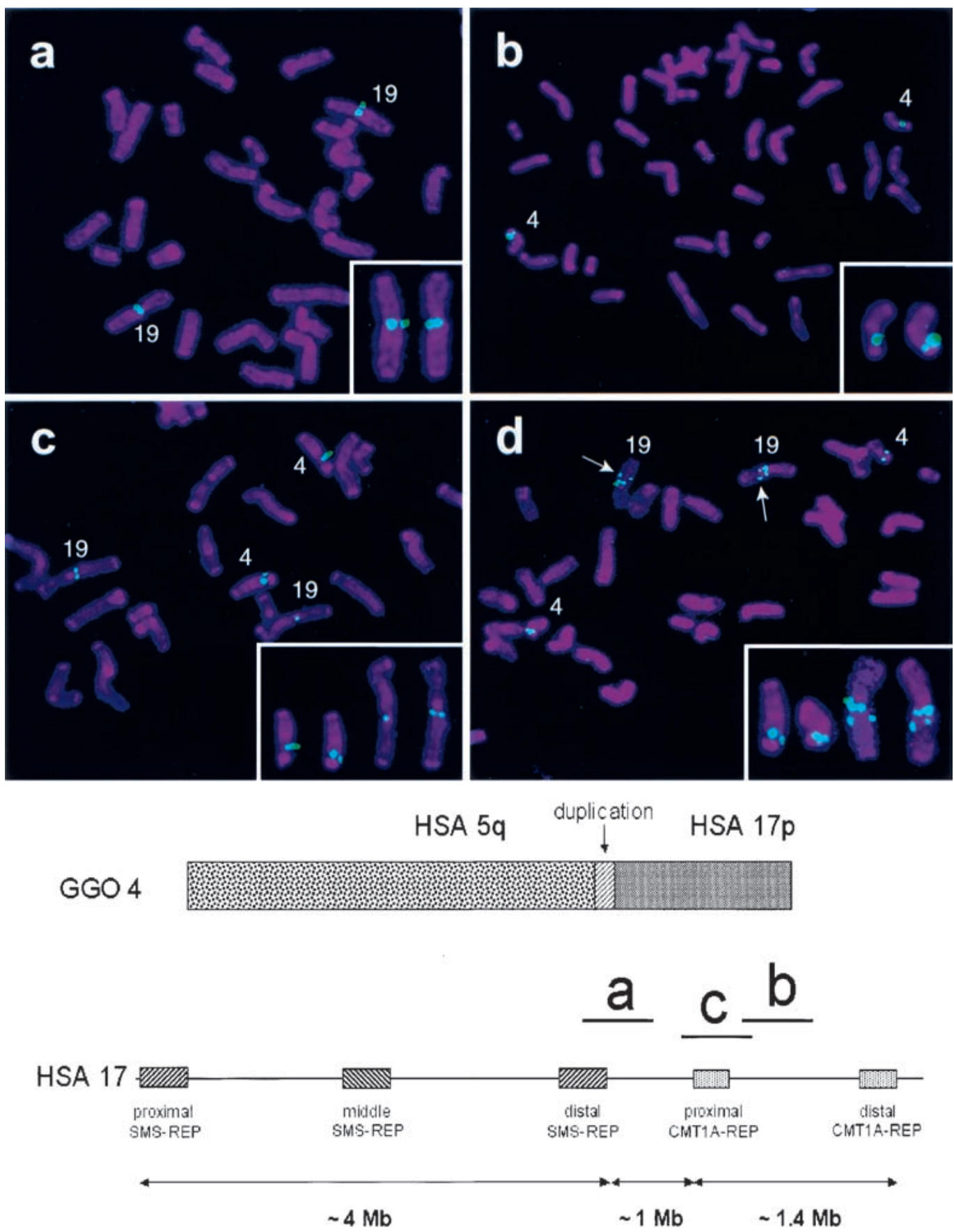

Figure 1 Gorilla metaphase chromosomes after hybridization with human BAC clones. Below is shown gorilla chromosome 4 (GGO 4), syntenic to human chromosomes 5 and 17. The vertical arrow indicates the $\sim 250 \mathrm{~kb}$ genomic duplication, originating from the GGO 19 segment, syntenic to human chromosome, (HSA) 17p12. Smith-Magenis syndrome low-copy repeats, SMS-REPs, and Charcot-Marie-Tooth disease type 1A low copy repeats, CMT1A-REPs, in the human chromosome 17p11.2p12 region are shown (telomere to right of figure) with the relative physical position of three BAC clones used in the FISH analysis that is shown above. (a) CTD-3157E16 (HSA 17p12), located proximal to the translocation breakpoint. (b) RP11-726O12 (HSA 17p12), located distal to the translocation breakpoint. (c) RP11-385D13 (HSA 17p12, proximal CMT1A-REP), spans the translocation breakpoint and includes the genomic duplication in gorilla. (d) CTC-428H11 (HSA 5q13.3) spans the breakpoint. Arrows within the FISH picture indicate an additional hybridization signal, which is also located on the long arm of GGO 19. This apparent duplication is located distal to the evolutionary breakpoint identified in this study. Small panels in the lower right corners demonstrate only the gorilla chromosomes 4 and 19 with positive probe hybridization signals.

Intriguingly, four nonoverlapping cosmids (4A10, 59E9, 4G3, and 123F7) (Murakami and Lupski 1996), each of which is contained entirely within two BACs spanning the translocation breakpoint, also revealed hybridization signals on both 
chromosomes 4 and 19, indicating that a chromosome segment of $\sim 250 \mathrm{~kb}$, syntenic to sequences surrounding the human proximal CMT1A-REP, is duplicated on GGO 4. The human chromosome fragment, homologous to the duplicated region in gorilla, is contained within the completely sequenced BAC clones: RP11-385D13, RP11-640I15, and CTD3157E16. Data-base searches in this human chromosome region identified several genes: HREP, NPD008/CGI-148 (RP11385D13); estrogen-responsive $\mathrm{B}$ box protein $(E R B P)$, zinc finger protein (ZNF286), and ubiquitin carrier protein (E2$E P F)$ (RP11-640I15); Meis1-related protein 2 (MRG2), and interleukin 6 signal transducer (CTD-3157E16). Within the BAC clone RP11-385D13 we also identified another gene: CMT duplicated region transcript 1 (CDRT1), located on the telomeric side of proximal CMT1A-REP, (Fig. 2) (Inoue et al. 2001).

Systematic FISH mapping with several ordered BACs on human chromosome 5q13.3 (Table 2) revealed one hybridization signal on GGO 4 (BACs CTD-2156N14, CTC-431G16, RP11-414A11, and CTD-2154O16) and GGO 19 (BACs CTD2064K14, RP11-580L9, CTC-2248H3, RP11-207B2, RP11393G17, and RP11-639J10). BAC clone CTC-428H11 showed signals on both gorilla chromosomes 4 and 19, indicating that the breakpoint maps between HMG-CoA reductase gene $(H M G C R)$ and RAS p21 protein activator 1 gene (RASA1) (Table 1). BLAST search results revealed that this clone also encompasses the histamine receptor $\mathrm{H} 2$ gene (HRH2), collagen type IV alpha-3 binding protein gene (COL4A3BP), and cyclin $\mathrm{H}$ gene $(\mathrm{CCNH})$. Interestingly, BAC CTC-428H11 showed an additional signal, both of which are located on the long arm of GGO 4 and HSA 5, demonstrating the presence of submicroscopic duplication on these chromosomes (Fig. 1d ).

\section{DISCUSSION}

Homologous recombination between nonallelic low-copy repeated sequences has been shown to be responsible for genomic rearrangements in several different regions of the human genome (for review, see Lupski 1998; Ji et al. 2000; Shaffer and Lupski 2000). LCRs can serve as substrates for both intra- or interchromosomal exchanges, thus making the respective genomic region unstable and prone to different meiotic and apparently mitotic rearrangements (e.g., deletions, duplications, inversions, and translocations).

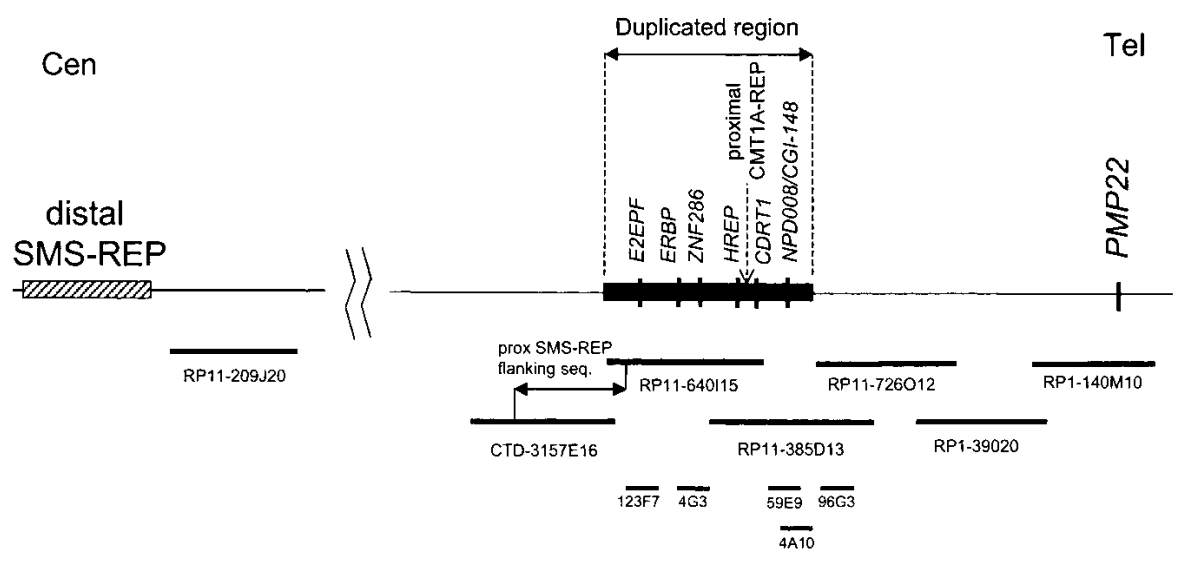

Figure 2 Schematic representation of the gorilla chromosome 19 duplicated region. Human BAC, PAC, and cosmid clones are shown below. Note that the proximal CMT1A-REP is not present in the gorilla genome. Its position in human is indicated with an arrow.
The human chromosome 17p11.2-p12 encompasses three Smith-Magenis syndrome low-copy repeats (SMS-REPs, $\sim 200 \mathrm{~kb}$ in size) (Chen et al. 1997) and two Charcot-MarieTooth disease type 1A low-copy repeats (CMT1A-REP; 24,011 bp) (Reiter et al. 1997). The proximal SMS-REP has been identified recently as the likely progenitor copy, which via duplication and duplication/inversion events at least 23.3 Mya (Kumar and Hedges 1998) resulted in distal and middle SMSREPs, respectively (Park and Lupski 2000). Two copies of CMT1A-REP have been found in chimpanzee and human, whereas only the distal copy, which includes a portion of the COX10 gene (Reiter et al. 1997), has been identified in gorilla, indicating that it must have been duplicated after the gorilla had diverged from a common human/chimpanzee ancestor (Kiyosawa and Chance 1996; Reiter et al. 1997; Boerkoel et al. 1999; Keller et al. 1999).

Our data indicate that chromosomes 4 and 19 in gorilla, previously identified as a product of reciprocal translocation between ancestral chromosomes, apparently arose as the result of complex chromosomal rearrangement. FISH experiments demonstrated that genomic clones from human chromosomes $5 \mathrm{q} 13.3$ and $17 \mathrm{p} 12$ span the gorilla reciprocal translocation breakpoints. Genomic sequence of these human BAC clones reveals no evidence of extensive stretches of homology or low-copy repeat sequences. The results of probing with unique sequence subclones from within the BAC clones that span the breakpoint revealed hybridization signals on both gorilla chromosomes 4 and 19, indicating genome microduplication of this region.

We propose a two-step event for the origin of the $t(4 ; 19)$ gorilla translocation. First, a $\sim 250 \mathrm{~kb}$ chromosome segment on gorilla chromosome $19 \mathrm{p}$, syntenic to the human chromosome region on $17 \mathrm{p} 12$ surrounding, but devoid of the proximal CMT1A-REP sequences, has been duplicated and inserted into the gorilla chromosome $4 \mathrm{q}$, homologous to human chromosome 5q13.3. The duplicated and inserted fragment made the respective genomic segments unstable and susceptible to recurrent, non-allelic homologous exchanges between both chromosomes 4 and 19. Such recurrent germ line chromosome translocations in humans have been recently shown to be caused by the misaligned opposite orientated repeated satellite III sequences in the de novo Robertsonian translocations (Shaffer and Lupski 2000) and by the palindromic orientated repeated sequences in the only known recurrent non-Robertsonian constitutional translocation $\mathrm{t}(11 ; 22)$ (Kurahashi et al. 2000; Edelman et al. 2001). Similar mechanism has been also proposed for the recurrent somatic translocation $\mathrm{t}(12 ; 15)(\mathrm{p} 13 ; \mathrm{q} 25)$ in congenital fibrosarcoma (Knezevich et al. 1998; Pujana et al. 2001) and may be responsible for the origin of the pericentric inversion of chimpanzee chromosome homologous to HSA 12q15, associated with a submicroscopic duplication (Nickerson 2000). Interestingly, BLAST search results of the overlapping BACs RP11-640I15 and CTD$3157 \mathrm{E} 16$ revealed the presence of an $\sim 120 \mathrm{~kb}$ chromosome segment, highly homologous to the se-

\section{Genome Research}


quences flanking the proximal SMS-REP. This LCR (LCR-PSFS: $\sim 120-\mathrm{kb}$ low copy repeat homologous to proximal SMS-REP flanking sequence) may be responsible for the origin of the described genomic duplication (Fig. 2). Alternatively, the $t(4 ; 19)$ could have arisen only once in testis of one pre-gorilla individual and was subsequently transmitted, implanted, and accumulated as heterozygous and fixed to the homozygous state due to inbreeding in a small "bottleneck population." The multi- versus single-exchange hypothesis could be investigated by analyzing the breakpoint polymorphisms (clusters) among three different subspecies of gorillas: Western Lowland, Eastern Lowland, and Mountain Gorilla.

We hypothesize that both chromosome events (duplication/insertion and translocation) occurred during male gametogenesis, thus increasing the number of progeny with both balanced derivative chromosomes. Supporting this, the vast majority of CMT1A duplication events in human arises during spermatogenesis (Palau et al. 1993; Lopes et al. 1997).

Recently, Mazzarella and Schlessinger (1998) estimated that up to $5 \%-10 \%$ of the human genome may be duplicated and Korenberg (2000) and Eichler (2000) emphasized the potential importance of chromosome duplication during primate speciation. We speculate that it was rather the described duplication and not the translocation that had an evolutionary selective advantage in homozygous or even in heterozygous carriers.

In summary, our data further indicate that higher order genomic architecture involving low-copy repeats resulting from genomic duplication plays a significant role in the genome evolution during primate speciation.

\section{METHODS}

\section{FISH and BLAST Analyses}

Because no gorilla genomic clones were commercially available, we applied human probes in FISH studies. Cosmid, PAC, and $\mathrm{BAC}$ probes specific for human chromosome regions $5 q 13.3$ and $17 \mathrm{p} 11.2$-p12 were identified from the existing physical maps of these regions (Murakami and Lupski 1996), (http://www.ncbi.nlm.nih.gov/). BAC and PAC clones were purchased from Research Genetics and from the BACPAC Resource Center (Pieter J. de Jong, www.chori.org/bacpac). DNA was isolated from liquid cultures using PSI $\psi$ Clone BAC DNA Kit (Princeton Separations). The relative alignments of the selective BACs were determined by BLAST searches against the high-throughput genome sequence database (http:// www.ncbi.nlm.nih.gov/blast/) and assembled using the Sequencher software (Gene Codes corp.). Genes and transcripts around both breakpoints were identified by a database search of the genomic sequences using the BLAST nonredundant database (http://www.ncbi.nlm.nih.gov/blast/).

The cell line CRL 1854 of Lowland Gorilla (Gorilla gorilla) was obtained from the American Type Culture Collection (http://www.atcc.org/). FISH mapping was performed on metaphases of peripheral blood lymphocytes (human) and Epstein-Barr virus transformed lymphoblasts (gorilla) according to a modified procedure of Shaffer et al. (1997). Briefly, 1 $\mu \mathrm{g}$ of isolated BAC, PAC, or cosmid DNA was labeled by nick translation using biotin (Life Technologies-GibcoBRL) or digoxigenin (Boehringer Mannheim) labeled nucleotides. Biotin was detected with FITC-avidin (Vector Labs) and digoxigenin was detected with rhodamine-anti-digoxigenin antibodies (Sigma). Chromosomes were counterstained with DAPI diluted in Vectashield antifade (Vector Labs). Cells were viewed under a Zeiss Axioskop fluorescence microscope equipped with appropriate filter combinations. Monochromatic images were captured and pseudocolored using
MacProbe 4.2.2/Power Macintosh G4 system (Perceptive Scientific Instruments).

\section{ACKNOWLEDGMENTS}

We thank Drs. N. Boerkoel, B. Morrow, D. Nelson, and L. Shaffer for critical reviews of the manuscript. We also thank M. Withers for excellent technical assistance. S.-S.P. is supported by a fellowship from the Korean government, and K.I. by a postdoctoral fellowship from the Charcot-Marie-Tooth Association. This study was supported in part by grants from the Muscular Dystrophy Association, the National Institute of Neurological Disorders and Stroke (R01 NS27042), and the National Institute of Child Health and Human Development (POI HD39420).

The publication costs of this article were defrayed in part by payment of page charges. This article must therefore be hereby marked "advertisement" in accordance with 18 USC section 1734 solely to indicate this fact.

\section{REFERENCES}

Arnold, N., Stanyon, R., Jauch, A., O'Brien, P., and Wienberg, J. 1996. Identification of complex chromosome rearrangements in the gibbon by fluorescent in situ hybridization (FISH) of a human chromosome $2 \mathrm{q}$ specific microlibrary, yeast artificial chromosomes, and reciprocal chromosome painting. Cytogenet. Cell Genet. 74: 80-85.

Boerkoel, C.F., Inoue, K., Reiter, L.T., Warner, L.E., and Lupski, J.R. 1999. Molecular mechanisms for CMT1A duplication and HNPP deletion. Ann. N. Y. Acad. Sci. 883: 22-35.

Chen, K-S, Manian, P., Koeuth, T., Potocki, L., Zhao, Q., Chinault, A.C., Lee, C.C., and Lupski, J.R. 1997. Homologous recombination of a flanking repeat gene cluster is a mechanism for a common contiguous gene deletion syndrome. Nat. Genet. 17: $154-163$.

Dutrillaux, B. 1979. Chromosomal evolution in primates: Tentative phylogeny from Microcebus murinus (Prosimian) to man. Hum. Genet. 48: 251-314.

Dutrillaux, B., Rethore, M.O., Prieur, M., and Lejeune, J. 1973. Analysis of the structure of chromatids of Gorilla gorilla. Comparison with Homo sapiens and Pan troglodytes. Humangenetik 20: 343-354.

Edelmann, L., Spiteri, E., Koren, K., Pulijaal, V., Bialer, M.G., Shanske, A., Goldberg, R., and Morrow, B.E. 2001. AT-rich palindromes mediate the constitutional $\mathrm{t}(11 ; 22)$ translocation. Am. J. Hum. Genet. 68: 1-13.

Eichler, E.E. 2000. The paralogous structure of the hominoid genome: Sites of rapid evolutionary turnover. (Session: Origin of Primate Evolution). Am. J. Hum. Genet. 67: Supp:54.

Haaf, T. and Bray-Ward, P. 1996. Region-specific YAC banding and painting probes for comparative genome mapping: Implications for the evolution of human chromosome 2. Chromosoma 104: $537-544$.

Inoue, K., Dewar, K., Katsanis, N., Reiter, L.T., Lander, E.S., Devon, K.L., Wyman, D.W., Lupski, J.R., and Birren, B. 2001. The $1.4 \mathrm{Mb}$ CMT1A duplication/HNPP deletion genomic region reveals unique genome architectural features and provides insights into recent evolution of new genes. Genome Res., 11: 1018-1033.

Jauch, A., Wienberg, J., Stanyon, R., Arnold, N., Tofanelli, S., Ishida, T., and Cremer, T. 1992. Reconstruction of genomic rearrangements in great apes and gibbons by chromosome painting. Proc. Natl. Acad. Sci. 89: 8611-8615.

Ji, Y., Eichler, E.E., Schwartz, S., and Nicholls, R.D. 2000. Structure of chromosomal duplicons and their role in mediating human genomic disorders. Genome Res. 10: 597-610.

Keller, M.P., Seifried, B.A., and Chance, P.F. 1999. Molecular evolution of the CMT1A-REP region: A human- and chimpanzee-specific repeat. Mol. Biol. Evol. 16: 1019-1026.

Kiyosawa, H. and Chance, P.F. 1996. Primate origin of the CMT1A-REP repeat and analysis of a putative transposon-associated recombinational hotspot. Hum. Mol. Genet. 5: 745-753.

Knezevich, S.R., McFadden, D.E., Tao, W., Lim, J.F., and Sorensen, P.H. 1998. A novel ETV6-NTRK3 gene fusion in congenital fibrosarcoma. Nat. Genet. 18: 184-187.

Koehler, U., Arnold, N., Wienberg, J., Tofanelli, S., and Stanyon, R. 1995a. Genomic reorganization and disrupted chromosomal 
synteny in the siamang (Hylobates syndactylus) revealed by fluorescence in situ hybridization. Am. J. Phys. Anthropol. 97: $37-47$.

Koehler, U., Bigoni, F., Wienberg, J., and Stanyon, R. 1995b. Genomic reorganization in the concolor gibbon (Hylobates concolor) revealed by chromosome painting. Genomics 30: $287-292$

Korenberg, J.R. 2000. Duplication and primate evolution. (Session: Origin of primate evolution). Am. J. Hum. Genet. 67: Supp:54.

Kumar, S. and Hedges, S.B. 1998. A molecular timescale for vertebrate evolution. Nature 392: 917-920.

Kurahashi, H., Shaikh, T.H., Hu, P., Roe, B.A., Emanuel, B.S., and Budarf, M.L. 2000. Regions of genomic instability on 22q11 and $11 \mathrm{q} 23$ as the etiology for the recurrent constitutional $t(11 ; 22)$. Hum. Mol. Genet. 9: 1665-1670.

Lopes, J., Vandenberghe, A., Tardieu, S., Ionasescu, V., Lévy, N., Wood, N., Tachi, N., Bouche, P., Latour, P., Brice, A., and LeGuern, E. 1997. Sex-dependent rearrangements resulting in CMT1A and HNPP. Nat. Genet. 17: 136-137.

Lupski, J.R. 1998. Genomic disorders: Structural features of the genome can lead to DNA rearrangements and human disease traits. Trends Genet. 14: 417-422.

Mazzarella, R. and Schlessinger, D. 1998. Pathological consequences of sequence duplications in the human genome. Genome Res. 8: $1007-1021$

McConkey, E.H. 1997. The origin of human chromosome 18 from a human/ape ancestor. Cytogenet. Cell Genet. 76: 189-191.

Müller, S., Rocchi, M., Ferguson-Smith, M.A., and Wienberg, J. 1997. Toward a multicolor chromosome bar code for the entire human karyotype by fluorescence in situ hybridization. Hum. Genet. 100: $271-278$.

Müller, S., Stanyon, R., Finelli, P., Archidiacono, N., and Wienberg, J. 2000. Molecular cytogenetic dissection of human chromosomes 3 and 21 evolution. Proc. Natl. Acad. Sci. 97: 206-211.

Murakami, T. and Lupski, J.R. 1996. A 1.5-Mb cosmid contig of the CMT1A duplication/HNPP deletion critical region in 17p11.2-p12. Genomics 34: 128-133

Nickerson, E. and Nelson, D.L. 1998. Molecular definition of pericentric inversion breakpoints occurring during the evolution of humans and chimpanzees. Genomics 50: 368-372.

Nickerson, E. 2000. "Molecular definition of pericentric inversions distinguishing the genomes of humans and chimpanzees since divergence from a common ancestor." Ph.D. dissertation, Baylor College of Medicine, Houston.

Palau, F., Löfgren, A., De Jonghe, P., Bort, S., Nelis, E., Sevilla, T., Martin, J.J., Vilchez, J., Prieto, F., and Van Broeckhoven, C. 1993. Origin of the de novo duplication in Charcot-Marie-Tooth disease type 1A: Unequal nonsister chromatid exchange during spermatogenesis. Hum. Mol. Genet. 2: 2031-2035.

Park, S.-S. and Lupski, J.R. 2000. Structure and primate evolution of the SMS-REP repeat gene cluster. Am. J. Hum. Genet. 67: Supp 2:67; 293.

Potocki L., Chen, K.-S., Park, S.-S., Osterholm, D.E., Withers, M.A., Kimonis, V., Summers, A.M., Meschino, W.S., Anyane-Yeboa, K., Kashork, C.D., Shaffer, L.G., and Lupski, J.R. 2000. Molecular mechanism for duplication $17 \mathrm{p} 11.2$ - the homologous recombination reciprocal of the Smith-Magenis microdeletion. Nat. Genet. 24: 84-87.

Pujana, M.A., Nadal, M., Gratacòs, M., Peral, B., Csiszar, K., González-Sarmiento, R., Sumoy, L., and Estivill, X. 2001. Additional complexity on human chromosome 15q: Identification of a set of newly recognized duplicons (LCR15) on 15q11-q13, 15q24, and 15q26. Genome Res. 11: 98-111.

Reiter, L.T., Murakami, T., Koeuth, T., Pentao, L., Muzny, D.M., Gibbs, R.A., and Lupski, J.R. 1996. A recombination hotspot responsible for two inherited peripheral neuropathies is located near a mariner transposon-like element. Nat. Genet. 12: 288-297. Erratum in: Nat. Genet. 1998. 19: 303.

Reiter, L.T., Murakami, T., Koeuth, T., Gibbs, R.A., and Lupski, J.R. 1997. The human COX10 gene is disrupted during homologous recombination between the $24 \mathrm{~kb}$ proximal and distal CMT1A-REPs. Hum. Mol. Genet. 6: 1595-1603.

Ried, T., Arnold, N., Ward, D.C., and Wienberg, J. 1993. Comparative high-resolution mapping of human and primate chromosomes by fluorescence in situ hybridization. Genomics 18: $381-386$

Shaffer, L.G., Kennedy, G.M., Spikes, A.S., and Lupski, J.R. 1997. Diagnosis of CMT1A duplications and HNPP deletions by interphase FISH: Implications for testing in the cytogenetics laboratory. Am. J. Med. Genet. 69: 325-331.

Shaffer, L.G. and Lupski, J.R. 2000. Molecular mechanisms for constitutional chromosomal rearrangements in humans. Аnпи. Rev. Genet. 34: 297-329.

Stanyon, R., Wienberg, J., Romagno, D., Bigoni, F., Jauch, A., and Cremer, T. 1992. Molecular and classical cytogenetic analyses demonstrate an apomorphic reciprocal chromosomal translocation in Gorilla gorilla. Am. J. Phys. Anthropol. 88: $245-250$.

Toder, R., Xia, Y., and Bausch, E. 1998. Interspecies comparative genome hybridization and interspecies representational difference analysis reveal gross DNA differences between humans and great apes. Chromosome Res. 6: 487-494.

Turleau, C., de Grouchy, J., and Klein, M. 1972. Chromosomal phylogeny of man and the anthropomorphic primates. (Pan troglodytes, Gorilla gorilla, Pongo pygmaeus). Attempt at reconstitution of the karyotype of the common ancestor. Ann. Genet. 15: 225-240.

Wienberg, J., Jauch, A., Lüdecke, H.J., Senger, G., Horsthemke, B. Claussen, U., Cremer, T., Arnold, N., and Lengauer, C. 1994. The origin of human chromosome 2 analyzed by comparative chromosome mapping with a DNA microlibrary. Chromosome Res. 2: $405-410$.

Wienberg, J., Stanyon, R., Nash, W.G., O'Brien, P.C.M., Yang, F., O'Brien, S.J., and Ferguson-Smith, M.A. 1997. Conservation of human vs. feline genome organization revealed by reciprocal chromosome painting. Cytogenet. Cell Genet. 77: 211-217.

Yu, D., Yang, F., and Liu, R. 1997. A comparative chromosome map between human and Hylobates hoolock built by chromosome painting. I Chuan Hsueh Pao 24: 417-423.

Yunis, J.J. and Prakash, O. 1982. The origin of man: A chromosomal pictorial legacy. Science 215: 1525-1530.

Received January 19, 2001; accepted in revised form March 22, 2001. 


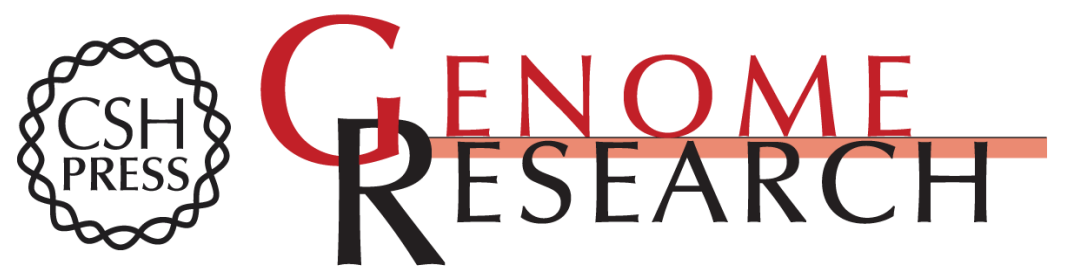

\section{The Evolutionary Chromosome Translocation 4;19 in Gorilla gorilla is Associated with Microduplication of the Chromosome Fragment Syntenic to Sequences Surrounding the Human Proximal CMT1A-REP}

Pawel Stankiewicz, Sung-Sup Park, Ken Inoue, et al.

Genome Res. 2001 11: 1205-1210

Access the most recent version at doi:10.1101/gr.181101

References This article cites 39 articles, 7 of which can be accessed free at: http://genome.cshlp.org/content/11/7/1205.full.html\#ref-list-1

License

Email Alerting Receive free email alerts when new articles cite this article - sign up in the box at the Service top right corner of the article or click here.

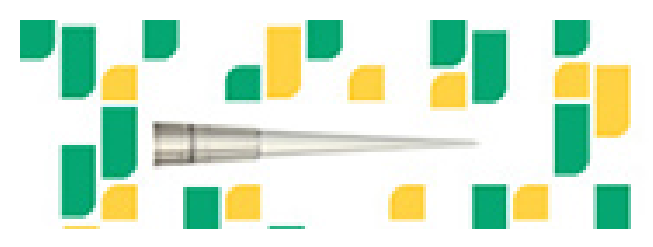

To subscribe to Genome Research go to: https://genome.cshlp.org/subscriptions 